\title{
Transnasal endoscopic medial maxillectomy in recurrent maxillary sinus inverted papilloma*
}

\author{
Reda H. Kamel, Ahmed F. Abdel Fattah, Ayman G. Awad \\ Department of Otorhinolaryngology, Cairo University, Cairo, Egypt
}

Rhinology 52: 381-385, 2014

DOI:10.4193/Rhino13.230

*Received for publication:

December 29, 2013

Accepted: May 26, 2014

\begin{abstract}
Background: Maxillary sinus inverted papilloma entails medial maxillectomy and is associated with high incidence of recurrence.

Objective: To study the impact of prior surgery on recurrence rate after transnasal endoscopic medial maxillectomy.

Methodology: Eighteen patients with primary and 33 with recurrent maxillary sinus inverted papilloma underwent transnasal endoscopic medial maxillectomy. Caldwell-Luc operation was the primary surgery in 12 patients, transnasal endoscopic resection in 20, and midfacial degloving technique in one. The follow-up period ranged between 2 to 19.5 years with an average of 8.8 years.

Results: Recurrence was detected in 8/51 maxillary sinus inverted papilloma patients (15.7\%), 1/18 of primary cases (5.5 \%), 7/33 of recurrent cases (21.2\%); $3 / 20$ of the transnasal endoscopic resection group (15\%) and 4/12 of the Caldwell-Luc group (33.3\%). Redo transnasal endoscopic medial maxillectomy was followed by a single recurrence in the Caldwell-Luc group (25\%), and no recurrence in the other groups.
\end{abstract}

Conclusion: Recurrence is more common in recurrent maxillary sinus inverted papilloma than primary lesions. Recurrent maxillary sinus inverted papilloma after Caldwell-Luc operation has higher incidence of recurrence than after transnasal endoscopic resection.

Key words: inverted papilloma, maxillary sinus, recurrence, endoscopic surgery, medial maxillectomy

\section{Introduction}

Sinonasal inverted papilloma (IP) is well known for marked propensity for recurrence and significant association with carcinoma ${ }^{(1)}$. Accordingly, radical surgery is indicated ${ }^{(2,3)}$. Maxillary sinus (MS) involvement by IP ranges between $26 \%{ }^{(4)}$ and $88 \%$ ${ }^{(5)}$ with an average of $50 \%{ }^{(1,2,6-8)}$. MS IP is aggressive, classified as an advanced stage, advised for more aggressive handling and reported with high incidence of recurrence ${ }^{(5-8)}$.

Surgery of MS IP ranges between medial maxillectomy via external lateral rhinotomy - previously postulated as the gold standard $^{(2,3)}$ - to recently exclusively transnasal endoscopic medial maxillectomy (TEMM) ${ }^{(9-13)}$.
The recurrence rate of IP in general ranges between $0 \%$ and $24 \%$ (14). Recurrence is higher in IP involving the MS ranging between $6.9^{(5)}$ and $27.2 \%{ }^{(4)}$. Recurrent MS IP is due to incomplete removal and is more difficult to handle ${ }^{(3,6,15)}$. To our knowledge, recurrence after TEMM in primary and recurrent MS IP has never been addressed.

The aim of this work is to report the recurrence rate after TEMM in primary and recurrent MS IP cases and to compare its incidence in relation to the type of prior surgery.

\section{Materials and methods}

Patients 
One hundred and thirty eight patients of IP without associated malignancy were operated upon by the senior author, between February 1991 and June 2013. Sixty five [47.1\%] cases originated from the MS. They underwent TEMM. Thirteen patients with follow-up less than two years and a single case lost to followup were excluded from the study. Four cases died of unrelated causes.

Amongst the 51 MS IP cases, there were 18 primary cases (35.3 $\%$ ) and 33 recurrent cases (64.7\%). Out of the 33 recurrent cases there were 20 cases $(60.6 \%)$ who were previously handled via a transnasal endoscopic resection, 12 (36.4\%) via Caldwell-Luc operation, and a single patient via midfacial degloving approach (3\%). None of the cases had prior medial maxillectomy via external lateral rhinotomy.

\section{Surgery}

TEMM was performed under general anaesthesia. The nasal part of the lesion was excised followed by total excision of the inferior turbinate. The medial wall of MS was removed including the nasolacrimal duct and the intra-maxillary part of the tumour was then excised. Utmost care was exerted to define the site/s of attachment of the IP within the MS. The limits of medial maxillectomy were the posterior wall of MS posteriorly, the orbital floor superiorly, the floor of the nose inferiorly, and the anterior wall of the MS anteriorly. The $45^{\circ}$ and $70^{\circ}$ telescopes were utilized to ensure proper exposure and manipulation of the whole anterior, inferior, and lateral MS walls as needed to achieve complete tumour resection. In case of a prior CaldwellLuc operation, pushing the anterior wall of the MS by a finger

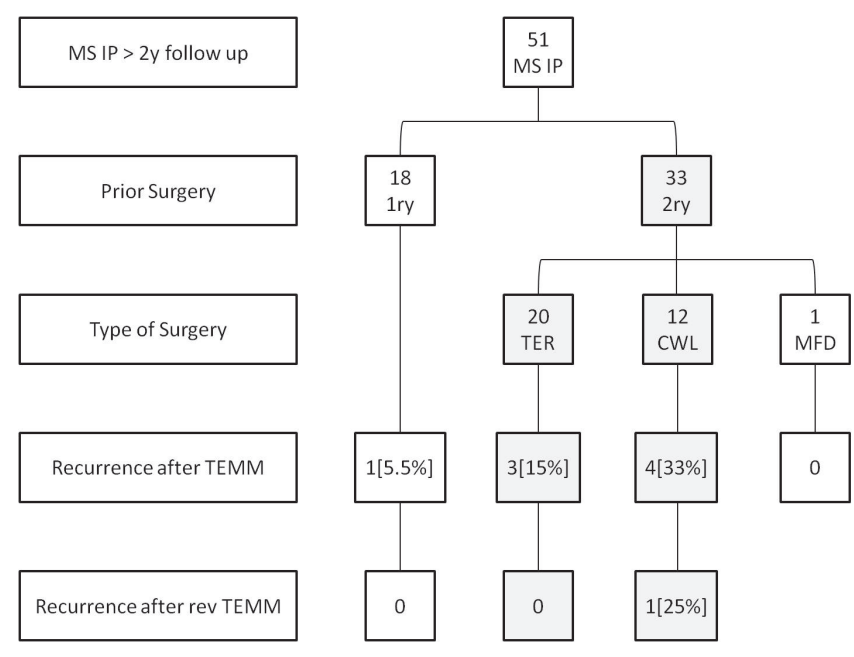

Figure 1. It shows prior surgery in maxillary sinus inverted papilloma, type of surgery, incidence of recurrence after transnasal endoscopic medial maxillectomy (TEMM) and revision TEMM. Maxillary sinus inverted papilloma (MS IP), transnasal endoscopic resection (TER), CaldwellLuc operation (CWL), and mid-facial degloving operation (MFD). from outside was resorted to help exposure and resection of any adherent residual IP under angled endoscopic monitoring. The MS mucosa was then removed and bone was drilled or curetted at the attachment site/s.

When the ethmoid, sphenoid and/or frontal sinus/s were colonized with a tumour, ethmoidectomy, sphenoid marsupialisation and/or extended frontal sinusotomy were also performed. In case of associated ethmoid, frontal, and/or sphenoid sinusitis, ethmoidectomy, frontal recess clearance, and/or sphenoidotomy were performed. Any associated polyps were also removed.

\section{Follow-up}

The patients received follow-up by endoscopic monitoring. CT with or without MRI studies were performed in case of suspected recurrence. A biopsy was taken and sent for histopathologic study. Redo TEMM was performed in case of proved recurrence.

\section{Results}

There were 34 males (66.7\%), and 17 females (33.3\%) whose age ranged between 24 and 72 years [average 49 years]. The tumor was right sided in 16 patients (31.4\%), and left sided in 35 patients $(68.6 \%)$.

The follow-up period ranged between 2 to 19.5 years with an average of 8.8 years. Recurrence was noticed in 8 out of the 51 cases of MS IP (15.7\%), one out of the 18 primary cases (5.5\%) and 7 out of the 33 recurrent cases (21.2\%). Recurrence was identified in 3 (15\%) of the 20 cases of the transnasal endoscopic resection group and 4 (33.3\%) of the 12 cases of the CaldwellLuc group (Figure 1). Recurrence was reported after a period of 7 months to 10.5 years with an average of 5 years.

Regarding the recurrence after redo TEMM, there were no recurrence $(0 \%)$ amongst the primary and transnasal endoscopic resection groups and a single recurrence in the Caldwell-Luc group (25\%). Recurrence was identified after 18 months (Figure I).

\section{Discussion}

In the pre-endoscopic era, medial maxillectomy via lateral rhinotomy was accepted as the treatment of choice in $\mathrm{P}^{(2,3)}$, but there is significant morbidity. The midfacial degloving procedure was introduced as an alternative technique to avoid the facial scarring ${ }^{(16)}$. Some authors recommended less aggressive external approaches such as the Denker's and Caldwell-Luc operation (17). However, the Caldwell-Luc operation was associated with high recurrence rates ${ }^{(5)}$.

With the rapid expansion of endoscopic sinus surgical techniques, the transnasal endoscopic resection was modified from very wide middle meatal antrostomy to partial medial maxillectomy ${ }^{(18)}$, and finally to complete TEMM ${ }^{(9-11)}$. However, few still advise an adjuvant external Caldwell-Luc operation ${ }^{(1,19,20)}$. Although many clinical studies have demonstrated the effecti- 

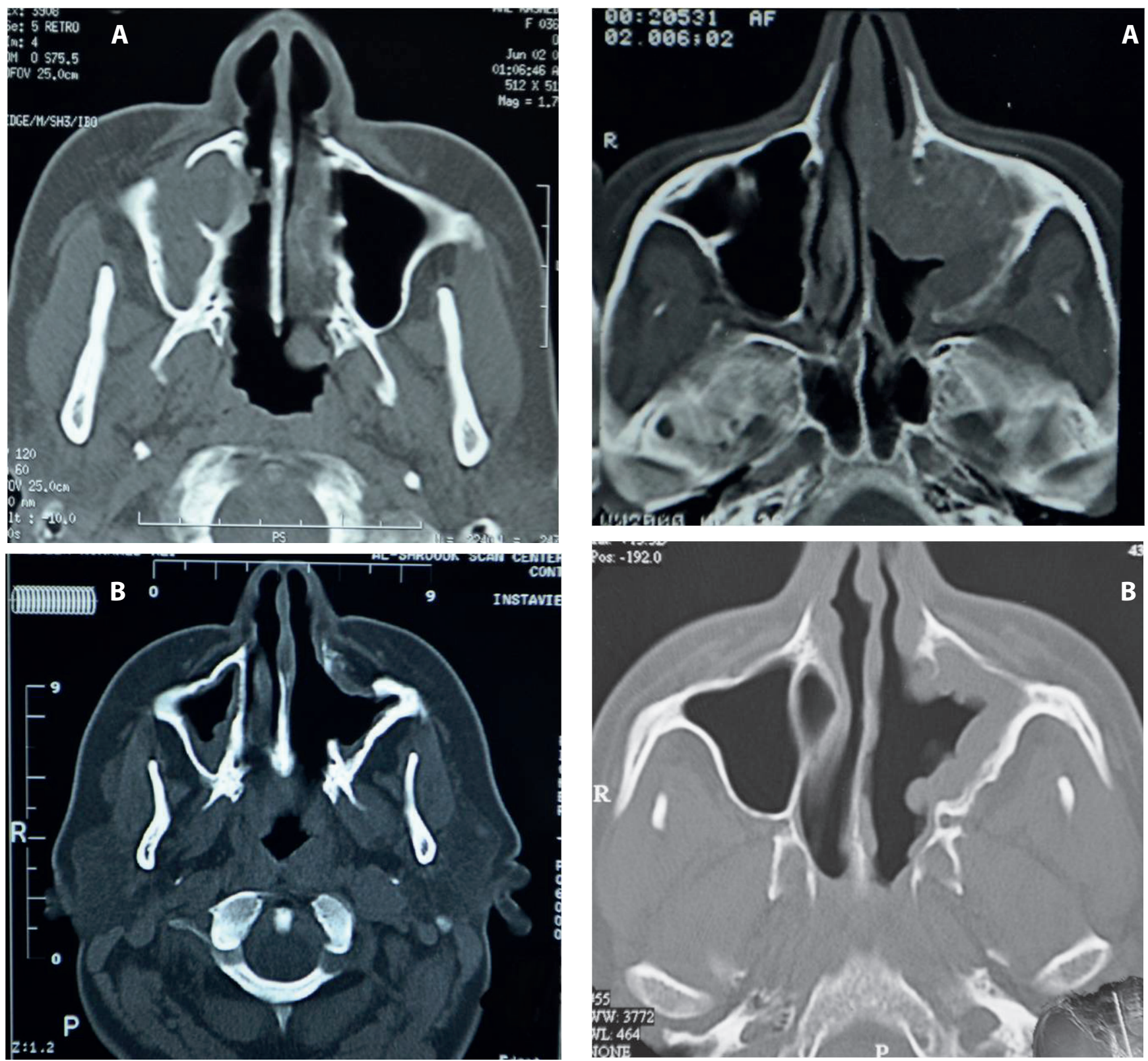

Figure 2. Recurrent MS IP after Caldwell-Luc operation. Notice the dehiscent anterior maxillary sinus bony wall, being replaced by fibrous tissue; (A), partial dehiscence of right MS anterior wall (B), extensive dehiscence of left MS anterior wall. It is difficult to dissect the recurrent IP off the fibrous anterior wall, with no clear plane of cleavage, during revision transnasal endoscopic medial maxillectomy. (MS: maxillary sinus, IP: inverted papilloma).

veness of the endoscopic approach for primary IP ${ }^{(21,22)}$, only a few published reports have studied the efficacy of the endoscopic approach for recurrent disease, and the surgical approach has been the subject of much debate ${ }^{(23)}$. In the current study, all MS IP cases were handled via TEMM including primary and secondary cases without any need for any adjuvant transcanine sinuscopy or Caldwell-Luc operation. Utmost care was exerted
Figure 3. Recurrent MS IP after transnasal endoscopic resection. (A) Notice the intact anterior maxillary sinus bony wall. (B) It is relatively easy to dissect the recurrent IP off the hard anterior bony wall during revision transnasal endoscopic medial maxillectomy. (MS: maxillary sinus, IP: inverted papilloma).

to keep integrity of bony sinonasal framework.

Reported recurrence rate of IP in general ranges between 0\% and $24 \%{ }^{(14)}$. The recurrence rate of external approaches varies from $0 \%$ to $36 \%{ }^{(2,3)}$, whereas the recurrence rate of transnasal endoscopic resection ranges between $0 \%$ and $25 \%{ }^{(24-27)}$. Recurrence is higher in IP involving the MS ranging between $6.9^{(15)}$ 
and $27.2 \%{ }^{(4)}$. In the current study, recurrence was noticed in 8 out of the 51 cases of MS IP (15.7\%) after TEMM and in 5 out of 60 cases of IP originating from other sites within the sinonasal region (8.3\%).

In general, recurrent IP tends to behave more aggressively and has a higher postoperative recurrence rate [17-31\%] than the primary lesion [0-12.5\%] ${ }^{(4,6,19,26,29)}$. In the current study, 7 out of the 33 recurrent MS IP cases showed recurrence (21.2\%) in contrast to one case out of 18 primary ones (5.5\%).

Most "recurrences" are, in fact, residual tumor; at tumor attachment site/s that had not been appropriately addressed $(3,6,15,19,26,28,29)$. Many factors might affect recurrence including surgical approach ${ }^{(9,10)}$.

Regarding the surgical approach, in the current study recurrence was identified in 3 out of 20 cases of the transnasal endoscopic resection group (15\%), 4 of the 12 cases of the Caldwell-Luc group (33.3\%). Moreover, after redo TEMM, one out of four cases demonstrated re-recurrence in the Caldwell-Luc group (25 $\%)$ and none in the primary and transnasal endoscopic resection groups (0\%). The higher incidence of recurrence after a Caldwell-Luc operation is attributed to difficulties encountered during revision surgery that obviates complete removal. The integrity of the bony sinonasal framework was insulted during prior surgery and the anterior wall of the MS was noticed to be soft, and difficult to manipulate transnasally. Fibrous tissue replaced the bony anterior wall of MS, in addition to marked adhesions to the recurrent tumour (Figure 2A, B). No clear plane of cleavage could be identified between the tumour and fibrous tissue that rendered complete excision of tumour with a safety margin very difficult. In such cases, pushing the anterior wall of the MS by a finger at the canine fossa from outside was resorted to help exposure and excision of any residual disease under endoscopic angled monitoring. This is in contrast to primary and post transnasal endoscopic resection cases where the intact anterior bony wall offers excellent chance for complete tumour excision, extirpation of surrounding mucosa and burring of underlying bone (Figure 3A, B).

\section{Conclusion}

1. Recurrence is more common in recurrent MS IP than primary lesions.

2. Recurrent MS IP after a prior Caldwell-Luc operation is associated with higher incidence of recurrence than those after transnasal endoscopic resection.

3. Revision surgery after Caldwell-Luc is more difficult than after transnasal endoscopic resection. This is due to difficult dissection of tumour off the fibrous anterior wall of the MS.

\section{Authorship contribution}

RHK: Performing all surgeries, Writing and revising the manuscript. AFAF: Data collection and analysis, Writing and revising the manuscript. AGA: Gathering data, and preparing table, Assistance in writing, and revising the manuscript,

\section{Conflicts of Interest}

None.

\section{References}

1. Lian F, Juan H. Different endoscopic strategies in the management of recurrent sinonasal inverted papilloma. J Craniof Surg 2012 23: 44-48.

2. Myers EN, Schramm VL, Barnes EL. Management of inverted papilloma of the nose and paranasal sinuses.Laryngoscope 1981; 91: 2071-2084.

3. Lawson W, LeBenger JL, Som P, Bernard PJ, Biller HF. Inverted papilloma: An analysis of 87 cases. Laryngoscope 1989; 99: 11171124

4. Lee TJ, Huang SF, Huang CC. Tailored endoscopic surgery for the treatment of sinonasal inverted papilloma. Head Neck. 2004; 26: 145-153.

5. Krouse $J \mathrm{H}$. Endoscopic treatment of inverted papilloma: safety and efficacy. Am J Otolaryngol. 2001; 22: 87-99.

6. Han JK, Smith TL, Loehrl T, Toohill RJ, Smith MM. An evolution in the management of sinonasal inverting papilloma. Laryngoscope. 2001;111: 1395-1400.

7. Kamel R, Khaled A, and Kandil T. Inverted papilloma: new classification and guidelines for endoscopic surgery. Am J Rhinol. 2005 19: 358-364.

8. Cannady SB, Batra PS, Sautter NB, Roh HJ, Citardi MJ. New staging system for sinonasal inverted papilloma in the endoscopic era. Laryngoscope. 2007; 117: 1283-1287.

9. Kamel RH. Transnasal endoscopic medial maxillectomy in inverted papilloma Laryngoscope. 1995; 105: 847-853.

10. Sukenik MA, Casiano R. Endoscopic medial maxillectomy for inverted papillomas of the paranasal sinuses: value of the intraoperative endoscopic examination. Laryngoscope. 2000; 110: 39-42.

11. Sadeghi N, Al-Dhahri S, Manoukian JJ: Transnasal endoscopic medial maxillectomy for inverting papilloma. Laryngoscope. 2003; 113: 749-753

12. Lund VJ, Stammberger $H$, Nicolai $P$ Castelnuovo $\mathrm{P}$, et al. European position paper on endoscopic management of tumours of the nose, paranasal sinuses and skull base. Rhinol Suppl. 2010; (22): 1-143.

13. Pagella F, Giourgos G, Matti E, Canevari FR,
Carena P. Endoscopic treatment of maxillary inverted papilloma. Rhinology. 2011; 49: 369-374.

14. Landsperg R. Attachment-oriented endoscopic surgical approach for sinonasal inverted papailloma. Oper Tech Otolaryngol. 2006; 17: 87-96.

15. Dragonetti A, Gera R, Sciuto A, et al. Sinonasal inverted papilloma: 84 patients treated by endoscopy and proposal for a new classification. Rhinology. 2011; 49: $207-$ 213.

16. Mangilia AJ, Philips DA. Midfacial degloving for the management of nasal, sinus and skull base neoplasm. Otolaryngol Clin North Am. 1995; 28: 1127-1143

17. Sanderson RJ, Knegt P. Management of inverted papilloma via Denker's approach. Clin Otolaryngol. 1999; 24: 69-71.

18. Kamel RH. Conservative endoscopic surgery in inverted papilloma. Arch Otolaryngol Head Neck Surg. 1992; 118: 649-653.

19. Buchwald CV, Larsen AS. Endoscopic surgery of inverted papilloma under image guidance - A prospective study of 42 con- 
secutive cases at a Danish university clinic Otolaryngol Head Neck Surg. 2005; 132 602-607.

20. Philpott CM, Dharamsi A, Witheford M, Javer AR. Endoscopic management of inverted papillomas: long-term results - the St. Paul's Sinus Centre experience. Rhinology. 2010; 48: 358-363.

21. Busquets JM, Hwang PH. Endoscopic Resection of Sinonasal Inverted Papilloma: A Meta-analysis. Otolaryngol Head Neck Surg. 2006; 134: 476-482.

22. Heathcote KJ, Nair SB. The impact of modern techniques on the recurrence rate of inverted papilloma treated by endonasal surgery. Rhinology. 2009; 47: 339-444.

23. Oikawa K, Furuta Y, Nakamaru Y, Oridate N, Fukuda S. Preoperative staging and surgical approaches for sinonasalinverted papilIoma. Ann Otolrhinollaryngol .2007; 116: 674-680.

24. Wormald PJ, Ooi E, van Hasselt CA, Nair S.
Endoscopic removal of sinonasal inverted papilloma including endoscopic medial maxillectomy. Laryngoscope 2003;113:867873.

25. Parida PK, Gupta AK. Medial maxillectomy: a comparative study as a surgical procedure. Otolaryngol Head Neck Surg. 2008; 138 192-199.

26. Tufano RP, Thaler ER, Lanza DC, Goldberg AN, Kennedy DW. Endoscopic management of sinonasal inverted papilloma. Am J Rhinol. 1999; 13: 423-426.

27. Cunningham K, Welch KC. Endoscopic medial maxillectomy. Oper Tech Otolaryngol. 2010; 21: 111-116.

28. Wolf SG, Schlosser RJ, Bolger WE, Lanza DC, Kennedy DW. Endoscopic and endoscopeassisted resections of inverted sinonasal papillomas. Otolaryngol Head Neck Surg 2004; 131: 174-179.

29. Minovi A, Kollert M, Draf W, Bochmuhl U. Inverted papilloma: feasibility of endonasal surgery and long-term results of 87 cases Rhinology. 2006; 44: 205-210.

Reda Kamel, M.D.

Professor of Rhinology

Cairo University

87 Manial Street

Manial

11451, Cairo

Egypt

Mobile: 002-012-22137172

E-mail: rhinology@redakamel.com rkamel55@hotmail.com

web site: www.redakamel.com 